\title{
Step temperature well testing
}

\begin{abstract}
Exact determination of thermal parameters is of high importance in a wide spectrum of both solid Earth investigations and subsurface geological and environmental studies. This article demonstrates a new revisited technique for the precise determination of formation thermal conductivity and contact thermal resistance in boreholes. We assume that the volumetric heat capacity of formations is a priori known, and the instantaneous heat flow rate and time data are available for the cylindrical probe located in borehole with a constant temperature. A dimensionless heat flow rate has been approximated by a new empirical equation, parameters of which were computed by use of the Newton method. An effectiveness of the proposed methodology is shown on modelled examples. A simulated case is given on example of metallic electrical heater placed into a vertical open (uncased) borehole.
\end{abstract}

Keywords: cylindrical probe, constant temperature, thermal conductivity, newton method
Volume 2 Issue 3 - 2017

\author{
Lev V Eppelbaum,' Izzy M Kutasov² \\ 'Department of Geosciences, Tel Aviv University, Israel \\ ${ }^{2}$ BYG Consulting Co, Boston, USA
}

Correspondence: Lev V Eppelbaum, Department of Geosciences, Tel Aviv University, Israel,

Email levap@post.tau.ac.il

Received: March 30, 2017 | Published: August 07, 2017

\section{Introduction}

In the set of potential geophysical fields, applied for solving different environmental and geological-geophysical problems (including hydrogeology, searching economic deposits, various engineering tasks, etc.), thermal parameters analysis plays one of the most significant roles. ${ }^{1-9}$ Therefore, any precision growth of the thermal parameters estimation will allow to increase accuracy of physical-geological model construction and to optimize a strategy of further investigations.

Due to the similarity in Darcy's and Fourier's laws, the same differential diffusivity equation describes the transient flow of incompressible fluid in porous medium and heat conduction in solids. ${ }^{10}$ As a result, a correspondence exists between the following parameters: volumetric flow rate, pressure gradient, mobility, hydraulic diffusivity coefficient and heat flow rate, temperature gradient, thermal conductivity and thermal diffusivity. Thus, it is reasonable to assume that similar to the techniques and data processing procedures of pressure borehole tests, can be applied to the temperature well tests. ${ }^{11,12}$

This means that the same analytical solutions of the diffusivity equation (at corresponding initial and boundary conditions) can be utilized for determination of the above-mentioned parameters. Earlier was proposed a semi-theoretical equation to approximate the dimensionless heat flow rate from an infinite cylindrical source with a constant bore-face temperature. This equation was used to process data of pressure and flow well tests and to develop a technique for determining the formation permeability and skin factor., ${ }^{3,10,13} \mathrm{~A}$ utilization of step-pressure test for determination of the formation permeability and skin factor was suggested in. ${ }^{3}$ During a step-pressure, test fluid is produced at two successive constant pressure flow periods. Application of this methodology is possible in both decreasing and increasing pressure sequences.

The objective of this paper consists in suggesting a similar technique for in situ evaluation of the values of formation thermal conductivity and thermal resistance of the borehole (expressed through the skin factor). We will consider below a long cylindrical electrical heater (with a large length/diameter ratio). Calculations conducted by $\mathrm{Mufti}^{1}$ revealed that for the practical purposes a cylinder with a length of 5 times (or more) exceeding its diameter could be accepted as an infinite cylinder. In this case, the heater can be considered as an infinite cylindrical source of heat. For this case, the temperature field in the borehole and around it is a function of:

1. Time

2. Radial distance

3. Thermal diffusivity of formations

4. Borehole thermal resistance. To evaluate the effect of the contact thermal resistance on the heat flow rate into formation, an effective radius concept is introduced.

An initial application of the basic idea was demonstrated in ${ }^{13}$ where the thermal permeability in boreholes was studied. This article demonstrates utilization of the same idea for the enhanced analysis of thermal conductivity.

\section{Effective radius of the heater}

To take into account the effect of probe's casing and the contact thermal resistance on the heat flow rate we will use an effective radius concept. This approach is widely used in transient pressure and flow well testing ${ }^{2}$ to evaluate the effect of formation damage (improvement) around the borehole on the pressure at the borehole's wall. Firstly, we introduce skin factor $(s)$-a parameter which allows to determine quantitatively the effect of the well's thermal resistance on the heat flow rate. In our case

$$
s=\left(\frac{\ddot{e}}{\ddot{e}_{e f}}-1\right) \ln \frac{r_{w}}{r_{h}},
$$

where $r_{w}$ is the well radius, $r_{h}$ is the radius of the heater, $\lambda$ is the thermal conductivity of formations (around the borehole), $\lambda_{e f}$ is the effective thermal conductivity of the $r_{w}-r_{h}$ annulus, and $r_{h a}^{e f}$ is the effective radius of the heater For an open (uncased) borehole the $r_{w}-r_{h}$ annulus is filled with the drilling fluid (or air) and mud cake-a plastic like coating of the borehole resulting from the solids in the drilling fluid adhering and building up on the wall of the hole. The $r_{w}-r_{h}$ ring in a cased borehole is composed of drilling fluid, steel, and cement. 
It is more convenient to express the skin factor through the apparent (effective) heater radius. ${ }^{2}$

$$
r_{h a}=r_{h} \exp (-s)
$$

Where $r_{h a}$ is the effective radius of the heater

\section{Dimensionless heat flow rate}

Let us assume that the thermal probe (at $r=r_{h}$ ) is maintained at a constant temperature of $T_{h}$, and the initial (undisturbed) temperature of formations is $T_{f}$. In this case a relationship between the heat flow rate per unit of depth $(q)$ and the time is:

$$
\begin{aligned}
& q=2 \pi \lambda\left(T_{h}-T_{f}\right) q_{D} \\
& t_{D}=\frac{\ddot{e} t}{\tilde{n} c_{p} r_{h a}^{2}}
\end{aligned}
$$

Where $q_{D}$ is the dimensionless heat flow rate, $\rho c_{p}$ is the volumetric heat capacity of formations, and $t_{D}$ is the dimensionless time.

We will assume that the volumetric heat capacity of formations is known. The function $q_{D}$ is expressed by a complex integral. Analytic expressions for the function $q_{D}=f\left(t_{D}\right)$ are available only for asymptotic cases or for the large values of $t_{D}$. Sengul ${ }^{14}$ numerically computed values of $q_{D}$ for a wide range of $t_{D}$. Below we will consider Sengul's values of $q_{D}$ as an "exact" solution of the above-mentioned integral. Chiu and Thakur suggested an empirical equation (Eq. (5)) for the function $q_{D}=f\left(t_{D}\right)$ :

$$
q_{D}=\frac{1}{c_{1} \ln \left[1+c_{2} \sqrt{t_{D}}\right]}, \quad c_{1}=0.982, \quad c_{2}=1.81 .
$$

The values of $q_{D}$ calculated after Eq. (5) and the results of a numerical solution, $q_{D}{ }^{*},{ }^{14}$ for various values of parameter $t_{D}$ are compared Table 1 . The agreement between values of $q_{D}$ and $q_{D}{ }^{*}$ calculated by these two methods shows a good correlation.

Table I Comparison of $q_{D}$ (Eq. (5)) and $q_{D} *[14]$ values for various $t_{D}$

\begin{tabular}{llllll}
\hline$t D$ & $q D$ & $q D^{*}$ & $t D$ & $q D$ & $q D^{*}$ \\
\hline 2 & 0.80203 & 0.80058 & 50 & 0.388 & 0.38818 \\
3 & 0.71739 & 0.7162 & 100 & 0.34523 & 0.34556 \\
5 & 0.62905 & 0.62818 & 200 & 0.31039 & 0.3108 \\
10 & 0.53438 & 0.53392 & 500 & 0.27337 & 0.27381 \\
20 & 0.46127 & 0.46114 & 1000 & 0.25054 & 0.25096
\end{tabular}

During a step-temperature test, the probe is heated at two successive constant temperature periods. Figure 1 illustrates the temperature distribution of a step-temperature test. For this methodology practical employment, either a decreasing or increasing temperature sequence may be applied.

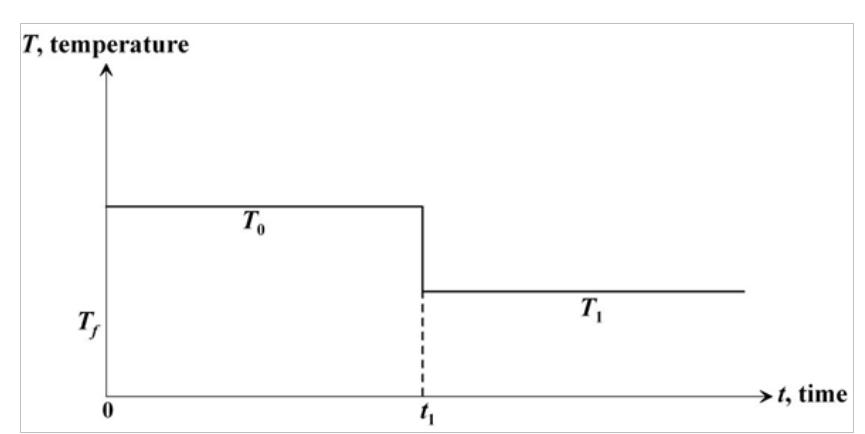

Figure I A step-temperature test: Schematic diagram.

\section{Working equations}

Application of the superposition principle to obtain the heat flow rate for the second heating period presented in Eq. (6):

$$
\begin{aligned}
& q(t)=2 \pi \lambda\left(T_{f}-T_{0}\right)\left[q_{D}\left(t_{D}\right)+\frac{\left(T_{0}-T_{1}\right)}{\left(T_{f}-T_{0}\right)} q_{D}\left(\Delta t_{D}\right)\right], \\
& t_{D 1}=t_{D} \frac{t_{1}}{t}, \quad \Delta t_{D}=t_{D} \frac{\Delta t}{t}, \quad \Delta t=t-t_{1} .
\end{aligned}
$$

During the second flow period, it is assumed that two heat flow rates were obtained $q_{a}=q\left(t=t_{a}\right)$ and $q_{b}=q\left(t=t_{b}\right)$. Then

$$
\begin{aligned}
& q_{a}=2 \pi \lambda\left(T_{f}-T_{0}\right)\left[q_{D}\left(t_{D a}\right)+\frac{\left(T_{0}-T_{1}\right)}{\left(T_{f}-T_{0}\right)} q_{D}\left(\Delta t_{D a}\right)\right], \\
& q_{b}=2 \pi \lambda\left(T_{f}-T_{0}\right)\left[q_{D}\left(t_{D b}\right)+\frac{\left(T_{0}-T_{1}\right)}{\left(T_{f}-T_{0}\right)} q_{D}\left(\Delta t_{D b}\right)\right] .
\end{aligned}
$$

Combining these two equations we can obtain an equation which can be used for estimating the dimensionless time $t_{D 1}$ :

$$
\begin{aligned}
& \frac{q\left(t_{a}\right)}{q\left(t_{b}\right)}=\frac{q D\left(t_{D a}\right)+\gamma q_{D}\left(\Delta t_{D a}\right)}{q D\left(t_{D b}\right)+\gamma q_{D}\left(\Delta t_{D b}\right)}, \\
& \gamma=\frac{p_{0}-p_{1}}{p_{i}-p_{0}}, \mathrm{t}_{\mathrm{Da}}=t_{D 1} \frac{t_{a}}{t_{1}}, \mathrm{t}_{\mathrm{Db}}=\mathrm{t}_{\mathrm{D} 1} \frac{t_{a}}{t_{1}} \\
& \Delta t D a=t D 1 \\
& \left.\frac{t_{a}}{t_{1}}-1\right), \quad \Delta t D a=t_{D 1}\left(\frac{t_{b}}{t_{1}}-1\right)
\end{aligned}
$$

To use a computer program, the last equation should be rewritten as

$$
y=\frac{q\left(t_{a}\right)}{q\left(t_{b}\right)}-\frac{q_{D}\left(t_{D a}\right)+\gamma q_{D}\left(\Delta t_{D a}\right)}{q_{D}\left(t_{D b}\right)+\gamma q_{D}\left(\Delta t_{D b}\right)}=\varepsilon,
$$

Where $\varepsilon$ is a small value and depends on the accuracy of the y ratio.

For solving Eq. (10) the Newton's method was applied. ${ }^{15}$ In this method, a solution of an equation is sought by defining a sequence of numbers which become successively closer and closer to the solution. The conditions, which guarantee that the Newton's method in our case will work and provide a unique solution, are satisfied. ${ }^{15}$ In the Eq. (10) the empirical function $q_{D}$ (see Eq. (5)) was used. In 
the subroutine utilizing the Newton method, the following parameters were employed: (a) the starting value of $t_{D 1}$ was 0.001 , (b) the time increment was 2, (c) the absolute accuracy of the ratio $y$ (see Eq. 10) was $e=0.0001$. When $N$ records of $q$ and $\Delta t$ are available, then $N(N-1) / 2$ values of $t_{D 1}$ can be computed and its average value can be calculated. ${ }^{16}$

From the of $t_{D 1}$ we can determine the skin factor

$$
r_{h a}=\sqrt{\frac{\ddot{e} t}{\tilde{n}_{c} t_{D 1}}}, \quad s=-\ln \frac{r_{h a}}{r_{h}} .
$$

The formation thermal conductivity is determined from Eq. (6). The thermal diffusivity of formations is estimated from the relationship

$$
a=\frac{\lambda}{p c_{p}}
$$

where $\rho$ is the formation's density and $c_{p}$ is the specific heat. The apparent (effective) heater radius and skin factor are calculated from Eqs. (2) and (4).

And, finally, the values of $\lambda_{e f}$ and $R$ are evaluated from Eq. (1)

$$
\lambda_{e f}=\frac{\lambda \ln \frac{r_{w}}{r_{h}}}{s+\ln \frac{r_{w}}{r_{h}}}, \quad R=\frac{1}{\lambda_{e f}}, \quad r_{w} \neq r_{h} .
$$

\section{Simulated example}

A metallic electrical heater is placed into a vertical open (uncased) borehole. The heater operated for ten hours and the transient heat flow rate was recorded. During first three hours, the temperature of the heater was $T_{0}=50^{\circ} \mathrm{C}$ and during the following 7 hours the heater temperature was increased on $10^{\circ} \mathrm{C}\left(T_{1}=60^{\circ} \mathrm{C}\right)$ (see schematic diagram in Figure 1). The borehole radius is $r_{w}=0.10 \mathrm{~m}$, the radius of the probe is $r_{h}=0.08 \mathrm{~m}$. The $r_{w}-r_{h}$ annulus consists of mud cake and drilling fluid. We assumed that the effective thermal conductivity of the $r_{w}-r_{h}$ annulus is $\lambda_{e f}=0.9741 \mathrm{~W} / \mathrm{m}^{\circ} \mathrm{C}$ and thermal contact resistance $R=1 / \lambda_{\text {ef }}=1.027 \mathrm{~m}^{\circ} \mathrm{C} / \mathrm{W}$. The initial formation temperature $\left(T_{f}\right)$ is $40^{\circ} \mathrm{C}$. The geological formation is sandstone with the density $\rho$ $=2300 \mathrm{~kg} / \mathrm{m}^{3}$, thermal conductivity $\lambda=2.0 \mathrm{~W} / \mathrm{m}^{\circ} \mathrm{C}$, and specific heat $c=783 \mathrm{~J} / \mathrm{kg}{ }^{\circ} \mathrm{C}$. Using the table presented in (Sengul, 1983) of $q_{D}=$ $f\left(t_{D}\right)$ and Eqs. (7) and (8) we generated the data for the aforementioned simulated example (Table 2, columns 2 and 3). The input data were chosen to allow to avoid interpolation of $q_{D}$ values. Indeed

$$
\begin{gathered}
a=\frac{\lambda}{c \rho}=\frac{2 \cdot 3600}{783 \cdot 2300}=0.0400 \mathrm{~m}^{2} h r^{-1}, \quad s=0.235, \\
t_{D}(1 \mathrm{hr})=\frac{0.0400 \cdot 1}{\left(0.08 \cdot e^{-0.235}\right)^{2}}=1.0 .
\end{gathered}
$$

The results of calculations after Eqs. (1) - (13) are presented in Table 2.

This example shows that the basic Eq. (5) can be used to compute the thermal conductivity of geological formations and contact thermal resistance. Indeed, the assumed and calculated values of $\lambda$ and $R$ are

\begin{tabular}{|c|c|c|c|c|c|}
\hline$\Delta \mathbf{t}_{1}, \mathbf{h r s}$ & $\begin{array}{l}\Delta \mathbf{t}_{2}, \\
\text { hrs }\end{array}$ & $\begin{array}{l}q_{1}, \\
W / m\end{array}$ & $\begin{array}{l}q_{2}, \\
W / m\end{array}$ & $\begin{array}{l}\lambda, \\
\mathbf{W} /\left(\mathbf{m} \cdot{ }^{\circ} \mathrm{C}\right)\end{array}$ & $\begin{array}{l}\mathbf{R}, \\
\mathrm{m} \cdot{ }^{\circ} \mathrm{C} / \mathrm{m}\end{array}$ \\
\hline I & 3 & 207.II & 165.5 & 2 & 1.048 \\
\hline I & 2 & 207.11 & 179.53 & 1.998 & 1.047 \\
\hline I & 4 & 207.II & 156.28 & 2.002 & 1.05 \\
\hline I & 5 & 207.II & 149.5 & 2.002 & 1.05 \\
\hline I & 6 & 207.11 & 144.2 & 2.003 & 1.051 \\
\hline I & 7 & 207.II & 139.88 & 2.003 & 1.051 \\
\hline 2 & 3 & 179.53 & 165.5 & 2.004 & 1.052 \\
\hline 2 & 4 & 179.53 & 156.28 & 2.005 & 1.053 \\
\hline 2 & 5 & I79.53 & 149.5 & 2.005 & 1.053 \\
\hline 2 & 6 & 179.53 & 144.2 & 2.005 & 1.054 \\
\hline 2 & 7 & I79.53 & 139.88 & 2.006 & 1.054 \\
\hline 3 & 4 & 165.5 & 156.28 & 2.007 & 1.055 \\
\hline 3 & 5 & 165.5 & 149.5 & 2.005 & 1.054 \\
\hline 3 & 6 & 165.5 & 144.2 & 2.006 & 1.055 \\
\hline 3 & 7 & 165.5 & 139.88 & 2.006 & 1.055 \\
\hline 4 & 5 & 156.28 & 149.5 & 2.004 & 1.053 \\
\hline 4 & 6 & 156.28 & 144.2 & 2.006 & 1.054 \\
\hline 4 & 7 & 156.28 & 139.88 & 2.006 & 1.055 \\
\hline 5 & 6 & 149.5 & 144.2 & 2.007 & 1.057 \\
\hline 5 & 7 & 149.5 & 139.88 & 2.008 & 1.057 \\
\hline 6 & 7 & 144.2 & 139.88 & 2.008 & 1.057 \\
\hline
\end{tabular}
in a very good agreement.
Table 2 Comparison of assumed and calculated value of formation thermal conductivity and thermal contact resistance. Assumed parameters: $\lambda=2.000$ $\mathrm{W} / \mathrm{m}^{\circ} \mathrm{C}, \mathrm{R}=1.027 \mathrm{~m}{ }^{\circ} \mathrm{C} / \mathrm{W}$

\section{Conclusion}

This article displays a new method for in situ determination of formation thermal conductivity and thermal resistance in the borehole. This method is based on a novel empirical equation based on utilization of the heat flow rate from an infinitely long cylindrical source with a constant bore-face temperature. Either decreasing or increasing temperature sequence may be used for this methodology application. It is important to note that this equation is valid for any (arbitarary) values of dimensionless time. This methodology needs in experimental application in boreholes drilled in different physicalgeological environments.

\section{Acknowledgements}

None.

\section{Conflict of interest}

The author declares no conflict of interest. 


\section{References}

1. Mufti IR. Geothermal aspects of radioactive waste disposal into the subsurface. Jour of Geophysical Research. 1971;76(35):8568-8585.

2. Earlougher RC. Advances in Well Test Analysis. Soc of Petrol Engineers New York, USA, 1977. 264 p.

3. Kutasov IM. Method Corrects API Bottom-hole Circulating-Temperature Correlation. Oil and Gas Jour. 1999;15:47-50.

4. Santoyo E, Santoyo S, García A, et al. Rheological property measurement of drilling fluids used in geothermal wells. Applied Thermal Engineering Jour. 2001;21(3):283-302.

5. Smerdon JE, Pollack HN, Cermak V, et al. Air-ground temperature coupling and subsurface propagation of annual temperature signals. Jour of Geophysical Research. 2004;109(D21107):1-10.

6. Andraverde J, Verma SP, Santoyo E. Uncertainty estimates of static formation temperature in boreholes and evaluation of regression models. Geophysical Jour. International. 2005;160(3):1112-1122.

7. Espinosa Paredes G, Morales Díaz A, Ulea Gonzalez U, et al. Application of a proportional-integral control for the estimation of static formation temperatures in oil wells. Marine and Petroleum Geology. 2009;26:259268.

8. Eppelbaum LV, Kutasov IM, Pilchin AN. Applied Geothermics. Springer London, UK, 2014. 751 p.
9. Majorowicz J, Chan J, Crowell J, et al. The first deep heat flow determination in crystalline basement rocks beneath the Western Canadian Sedimentary Basin. Geophysical Jour International. 2014;197:731-747.

10. Kutasov IM, Eppelbaum LV. Pressure and Temperature Well Testing. CRC Press. 2015. 325 p.

11. Muskat M. Flow of Homogeneous Fluids through Porous Media. JW Edwards Inc, Ann Arbor. USA, 1946. 763 p.

12. Eppelbaum LV, Kutasov IM. Temperature and pressure drawdown wel testing: Similarities and differences. Jour of Geophysics and Engineering. 2006;3(1):12-20.

13. Kutasov IM, Kagan M. Cylindrical probe with a constant temperaturedetermination of the formation thermal conductivity and contact thermal resistance. Geothermics. 2003;32(2):187-193.

14. Sengul MM. Analysis of Step-pressure Tests. SPE Paper 12175 presented at the $58^{\text {th }}$ Ann. San Francisco, California, USA, 1983.

15. Grossman SI. Calculus. USA: Academic Press; 1981. 716 p.

16. Chiu K, Thakur SC. Modeling of Wellbore Heat Losses in Directional Wells Under Changing Injection Conditions. SPE 2287, Presented at the $66^{\text {th }}$ Annual Techn Conf and Exhib of the Society of Petr Engin. Dallas, USA, 1991. p. 6-9. 